\title{
Sexual Differences in Hibernation of Hedgehogs in New Zealand
}

\author{
Zróżnicowanie płciowe u hibernujących jeży w Nowej Zelandii
}

\author{
John P. PARKES \& Robert E. BROCKIE
}

\begin{abstract}
Parkes J. P. \& Brockie R. E., 1977: Sexual differences in hibernation of hedgehogs in New Zealand. Acta theriol., 22, 29: 384-386 [With 3 Figs.].

The winter activity of European hedgehogs was monitored in two locations in New Zealand. Parts of both populations were not hibernating on any given night during the winter. Throughout the winter, and particularly towards the end of winter, male hedgehogs were up to three times more common than females, suggesting their more frequent and earlier arousals from hibernation. Differences between the two populations were thought to be caused by differences in the condition of the animals rather than climatic differences.

[Protect. Forest Divis., Forest. Res. Inst., P.O. Box 31-011 Christchurch, (JPP) and Ecol. Divis., Dept. Sci. Indust. Res., P.O. Box 30466, Lower Hutt, New Zealand (REB)]
\end{abstract}

Laboratory studies in Finland have shown that hedgehogs Erinaceus europaeus (Linnaeus, 1758) can arouse from their hypothermia throughout the season of hibernation, and that towards the end of winter, individual animals, especially males, may shorten the periods spent in hypothermia (K ris t of f e r s s on \& S o ivio, 1964, 1967).

In New Zealand, two independent mark-recepture field studies on hedgehogs were made, from January 1970 to June 1971 on a dairy farm at Palmerston North (P a rkes, 1976), and from September 1970 to September 1972 on a golf course $100 \mathrm{~km}$ further south at Lower Hutt (B r o c k i e, 1974). The animals were found by searching the study areas at night using powerful hand held torches. The sex of each captured hedgehog was noted, 345 being sexed on 714 occasions at Palmerston North and 207 animals being sexed on 505 occasions at Lower Hutt.

The sex ratio in summer, when all animals were presumably equally observable, did not differ significantly from unity at either place. However, throughout the winter, and particularly towards the end of winter, males were up to three times more common than females (Fig. 1). The difference was significant $(p<0.05)$ in October at Palmerston North and in August and September at Lower Hutt.

To our knowledge, this difference in hibernating behaviour has not been noted in wild hedgehogs in Europe although the limited evidence from the six caged Finnish animals suggests the phenomenon may be general.

The season of hibernation, measured by the decrease in total numbers of observable hedgehogs (Fig. 2) was apparent in the Palmerston North study, extending from July until October. At Lower Hutt, no such clear delineation of the hibernating season was apparent, although minimum levels of activity were reached as early as May. 


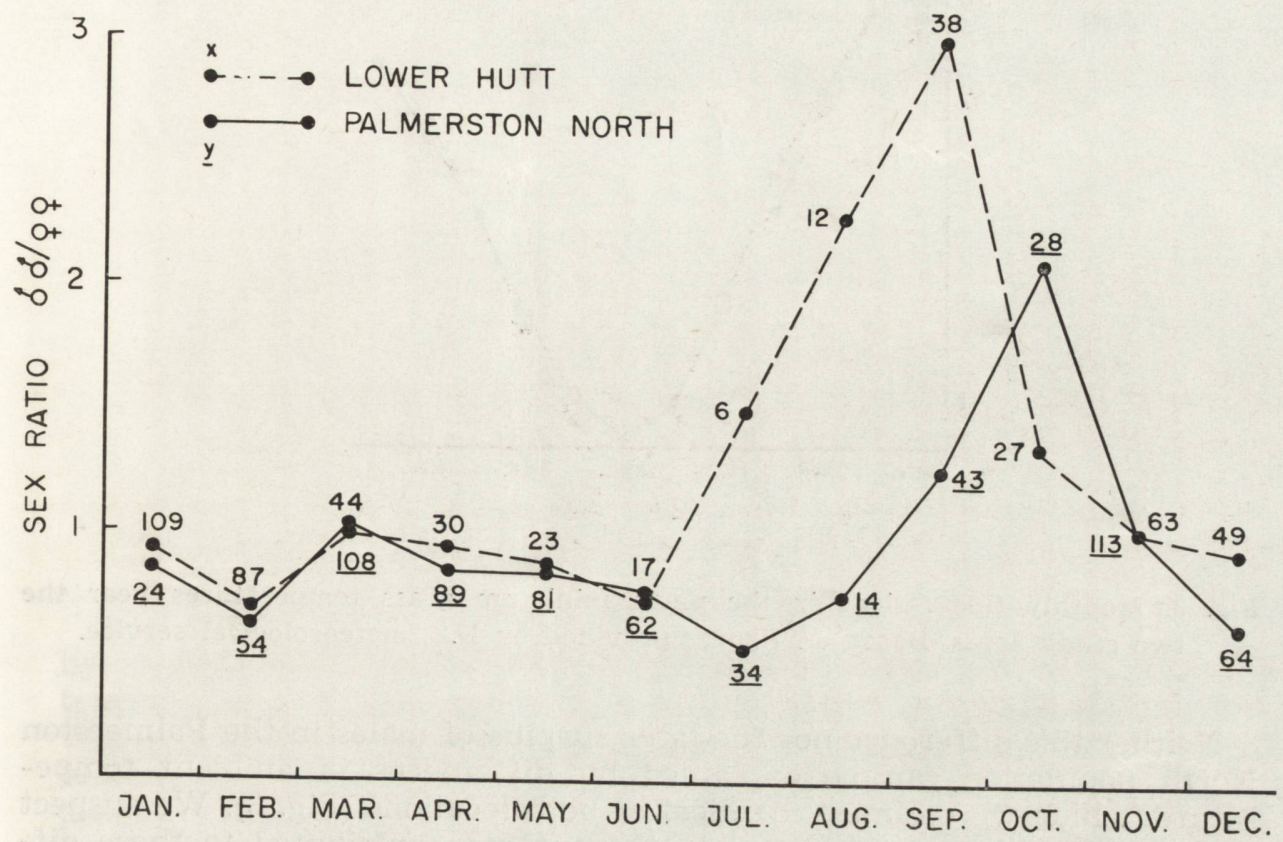

Fig. 1. Monthly fluctuation in the sex ratio of wild hedgehogs caught on two study areas in New Zealand. Sample sizes are attached.

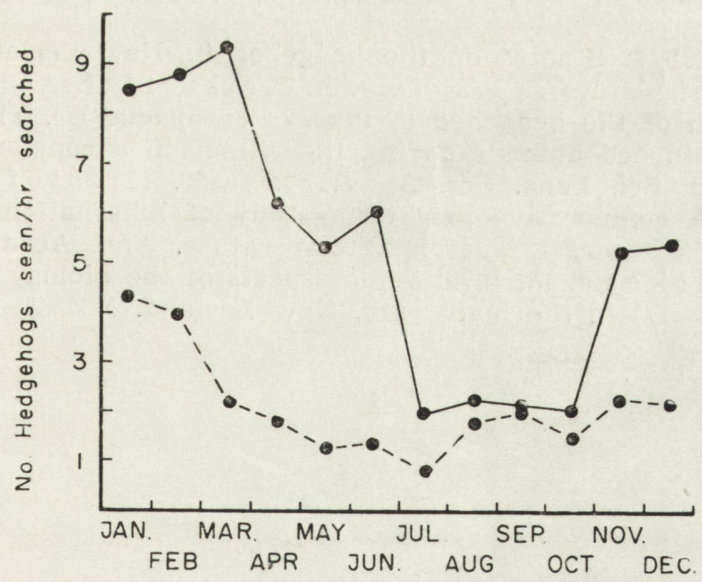

Fig. 2. Monthly fluctuation in the number of hedgehogs seen/hnur searched in two areas in New Zealand. 


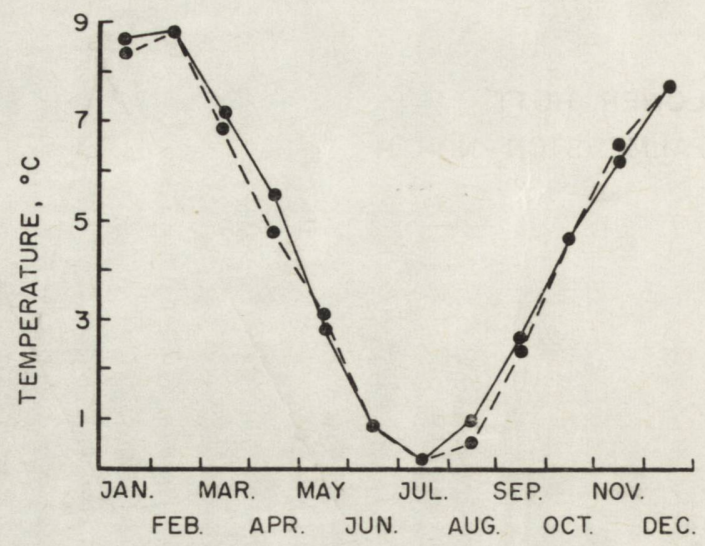

Fig. 3. Monthly fluctuations in the mean minimum grass temperatures near the two study areas. Based on figures provided by N.Z. meteorological service.

Neither this difference nor the later surplus of males in the Palmerston North population can be explained by differences in ambient temperature, which were almost identical at both locations (Fig. 3). We stspect that the quantity of fat stored in the autumn contributed to these differences, because, during May and June, the mean weight of male hedgehogs captured at Palmerston North lay between 750 and $800 \mathrm{~g}$ while those at Lower Hutt averaged between 640 and $700 \mathrm{~g}$. The extra fat on the Palmerston North animals may have enabled them to remain longer in hibernation.

\section{REFERENCES}

B rockie R. E., 1974: Studies on the hedgehog in New Zealand. Unpublished Ph. D. Thesis, Victoria University, Wellington. Kristoffersson R. \& S sivio A., 1964: Hibernation of the hedgehog (Erinaceus europaeus L.). The perioditity of hibernation of undisturbed animals during the winter in a constant ambien temperature. Ann. Acad. Sci. Fenn. Ser. A IV, 80: 1-22. K r is t offers s on R. \& Soivio A., 1967: A comparative long term study of hibernation in Finnich and German hedgehogs in a constant ambient temperature. Ann. Acad. Sci. Fem. Ser. A IV, 122: 1-23. P a rkes J. P., 1976: Some aspects of the biology of the heigehog (Erinaceus europaeus L.) in the Manawatu, New Zealand. N.Z. J. Zool., 2: 463-72.

Accepted, March 18, 1977. 